\title{
A Longitudinal Study Involving The Utilization Of A Team-Oriented Structure And An Enterprise Resource Planning Framework In A Medium-Sized Organization
}

Leo R. Simpson, (E-mail: iamleo@sbu.edu), Western Kentucky University John G. Watson, (E-mail: jwatson@ @sbu.edu), St. Bonaventure University

\begin{abstract}
The paper provides an analysis of a custom manufacturer facing issues of growth, productivity concerns, changes in technology, competitive threats, financial management, marketing development, and internal human resource responsibilities, and the response to these issues. The paper traces the changes that took place in this medium-sized organization over a fifteen-year period in order to improve the culture of the company. The implementation of a team oriented structure utilizing an external change agent, and the reorganization of employee responsibilities in a major restructuring effort are discussed. A new enterprise resource planning system (ERP) was implemented to operate and coordinate the company. The authors analyze in detail the evolution that has taken place in the company over the last four years. The major benefits and learnings of the change are presented.
\end{abstract}

\section{INTRODUCTION}

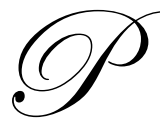

roductivity and organizational effectiveness are the hallmarks of organizations that are able to compete in modern markets. When faced with internal organizational inefficiencies and external competitive threats, many organizations fail to restructure to provide for growth and modern technology, and as a result get outflanked by strong international competition that is more flexible in dealing with the demands of modern industry. Custom manufacturers are even more susceptible to rapid change since the customer is paying for current technology and rapid responsiveness.

The paper provides an analysis of a custom manufacturer facing issues of growth, productivity concerns, changes in technology, competitive threats, financial management, marketing development, and internal human resource responsibilities, and the response to these issues. A longitudinal analysis examines the efforts of an external change agent working with the company attempting to develop a team-based structure within the company, reorganizing employee responsibilities in a major restructuring effort, and developing a new enterprise resource planning system to operate and coordinate activities in the company. The company employs 350 individuals and manufactures large custom packaging equipment sold internationally. The evolution of the present organization over the last four years is analyzed in detail. The organization has gone through significant restructuring; the philosophy of management has changed; employees and teams have been empowered; sales have almost doubled; and, many other major changes have resulted. The analysis is a chronological examination of key events contributing to this evolution. 


\section{LITERATURE REVIEW}

In making the decision during reorganization to a team-based structure in an attempt to change the culture of the company a significant number of factors was considered. First, a review was made of corporate culture and how corporate culture impacts the effectiveness of a company. Second, a review of the successes and/or failures with the utilization of teams in organizations was reviewed. Third, the benefits of implementing a TQM approach in organizations was studied. Finally, Enterprise Resource Planning systems were investigated.

\section{Cultural Change}

Corporate culture consists of the pattern of basic assumptions, values, attitudes, beliefs and expectations shared by members of an organization that guide their behavior (Greenberg \& Baron, 2003). It is differences in organizational culture that cause two organizations to "feel" completely different to workers and visitors (Schein, 1992). Corporate culture is the personality of the organization (Kilman, Saxton, Serpa, 1985). Through education and participation in work activities, people derive assumptions and learn satisfactory ways to solve business problems. The company culture at the beginning of the change process was fundamentally autocratic in nature. In order for the company to move forward, it was necessary for the culture to become conducive to motivating employees, shaping their values, governing organizational arrangements, and influencing the way information was to be processed. A fundamental departure from the traditional autocratic top down format was required. It was realized this shift would not be easy. It would be cumbersome; however, to meet organizational objectives, it was necessary. Successful change required altering the flow of information, redistributing authority, redesigning jobs and work processes, and developing people skills.

\section{Fostering a Collaborative Environment and a Team-Oriented Structure}

\section{Collaboration}

According to Schrage (1995), "Collaboration describes a process of value creation that our traditional structures of communication and teamwork cannot achieve." He defines "collaboration" as " the process of shared creation: two or more individuals with complementary skills interacting to create a shared understanding that none had previously possessed or could have come to on their own. Collaboration creates a shared meaning about a process, a product, or an event".

The quality and intensity of collaborative relationships and the types of interaction associated with them evolve over the course of the collaboration. Schrage (1995) calls collaboration "a state of grace we switch into and out of as the moment and the task demand". It can occur formally when management commissions a task force, or informally, when two people start a conversation at the lunch table. The stimulus for collaboration is people realizing they cannot do it themselves. The medium for collaboration is the relationship.

\section{Groups}

Groups are widely recognized as an important sociological and social psychological unit of analysis in the study of organizational behavior (Turner, 2001). The term group can be defined in a number of different ways. A comprehensive definition would say that if a group exists in an organization, its members:

1. $\quad$ Are motivated to join

2. Perceive the group as a unified unit of interacting people

3. Contribute in various amounts to the group processes (that is, some people contribute more time or energy to the group than do others)

4. Reach agreements and have disagreements through various forms of interaction (Ivancevich and Matteson, 1993). 


\section{Teams}

Katzenbach and Smith (1993) define a team as "a unit of performance that differs from the individual or the entire organization. A team is a small group of people with complementary skills committed to a common purpose and a set of specific performance goals". They classify teams according to function: teams that make or do things; teams that recommend things; and teams that run things. Katzenbach and Smith (1993) also cite the following specific differences between work groups and teams:

1. The work group has a strong, clearly focused leader; the team has shared leadership roles.

2. The work group has individual accountability; the team has individual and mutual accountability.

3. The work group's purpose is the same as the organization's; the team has a specific purpose.

4. The work group has individual work-products; the team has collective work-products.

5. The work group runs efficient meetings; the team encourages open-ended, active problem-solving meetings.

6. The work group measures effectiveness indirectly (for example, financial performance of the overall business); the team measures performance directly by assessing collective work-products.

7. The work group discusses, decides, and delegates; the team discusses, decides, and does real work.

The utilization of teams in today's organizations is becoming a commonly prevalent phenomenon. Teambased organizations are becoming firmly established in the organizational setting. Years ago there were few organizations that used teams. Today the antithesis is true. Recent data show that 80 percent of Fortune 500 companies have half or more of their employees on teams. Furthermore, 68 percent of small U.S. manufacturers are using teams in their production areas (Joinson 1999; Strozniak 2000).

Estimates of the prevalence and type of teams among Fortune 1000 companies are as follows:

\section{Types of Teams}

1. Almost all use project teams (diverse managerial/professional employees working on projects for a defined, but typically extended, period of time).

2. A large majority use parallel teams (employees working on problem-solving or quality teams in parallel to the regular organizational structure).

3. A majority use permanent work teams (self-contained work units responsible for manufacturing products or providing services). (Offermann and Spiros, 2001).

In reviewing the experiences organizations have had with work teams, the literature suggests there were mixed results with the use of teams. One study involved asking the officials of organizations that use teams about their results of using teams. (Lawler, Mohrman, \& Ledford, 1992). The sample consisted of several hundred of the 1,000 largest companies in the United States. Approximately 47 percent of the organizations used some type of work teams, and they were typically not used throughout the entire organization. In general, the teams were highly regarded and became increasingly popular over time. Other research showed that much of organizational experience has demonstrated that teams of employees are more productive, more creative, and better able to meet the challenges of an increasingly dynamic business environment (Townsend and DeMarie, 1996). Positive results are further supported by in-depth case studies of numerous teams in many organizations (Hackman, 1990). However, the use of work teams does not assure improvements in an organization. There are failed attempts at introducing teams into the workplace, and a variety of reasons have been cited as to why work teams fail. Certain pitfalls can be avoided (Robbins \& Finley, 1995).

According to research on group processes, teams are most appropriate when the task is complex and requires individuals with varied skills and competencies to work together. Some researchers emphasize the importance of selecting the right individuals based upon a team member's knowledge, skills, abilities, and other characteristics (LePine, Hanson, Borman, Motowidlo, 2000; Stevens \& Campion, 1994, 1999). 


\section{Emergence of Cross-Functional, Virtual, and Self-Managed Teams}

In many organizations today significant attention continues to be given to the dynamics of teams and the emergence of cross-functional, virtual, and self-managed teams.

\section{Cross Functional Teams}

Cross functional teams are composed of individuals from a variety of departments and are formed based upon the recognition of dysfunctional bureaucratic functional autonomy (Luthans, 2004). According to Chaudron (1995), organizations can carry out five steps to improve the coordination of cross-functional teams: (1) choosing the membership carefully, (2) clearly establishing the purpose of the team, (3) ensuring that everyone understands how the group will function, (4) conducting intensive team building up front so that everyone learns how to interact effectively, and (5) achieving noticeable results so that morale remains high and the members can see the impact of their efforts. Recent research evidence shows that functional breadth and cross-training of team members improves information sharing, team interaction and team performance (Marks, Sabella, Burke and Zaccaro, 2002).

\section{Virtual Teams}

Virtual teams are groups of people who work interdependently with shared purpose across space, time, and organization boundaries using technology to communicate and collaborate (Kirkman, Rosen, Gibson, Teslik and McPherson, 2002). While the use of virtual teams is rapidly expanding, research efforts are needed to assist in making them effective.

\section{Self-Managed Teams}

The use of self-managed teams has become widespread. Self-managed teams consist of a group of employees who are responsible for managing and performing technical tasks that result in a product or service being delivered to an internal or external customer (Yeatts and Hyten, 1998). A comprehensive analysis of 70 studies of self-managed teams showed a positive impact on productivity and specific attitudes related to the team, but not on general attitudes, absenteeism, or turnover (Goodman, Devados, and Hughson, 1988). An in-depth interview of 4,500 teams at 500 organizations (1993) uncovered a host of factors leading to ineffectiveness including:

1. Team members aren't willing to give up past practices or set aside power and position.

2. Not all team members have the ability, knowledge, or skill to contribute to the group. Team functioning slows because some members shoulder more responsibility than others.

3. As team members, workers often face conflicts or challenges to their own personal beliefs. What works for the group often does not work for the individual.

Finally, based upon the research evidence to date and the practical experience in many organizations, team effectiveness can be enhanced by the following: team building, collaboration, leadership, and understanding of cultural issues in global situations (Luthans, 2004).

\section{Total Quality Management}

In order to provide the highest quality products and services which meet or exceed the needs of consumers, most organizations have adopted total quality programs. Total Quality Management (TQM) involves a commitment to excellence that typically involves teamwork and a process of continuous improvement (Brown \& Harvey 2001). TQM had its beginning with the work of Walter A. Shewart in the 1930's. Three of the leading "gurus" on TQM are W. Edwards Deming, Joseph Juron, and Phil Cosby. As a result of the work of Deming in Japan, Japanese companies have improved quality and productivity and dominate many world markets (Deming 1986). Some of the basic elements of TQM include employee involvement and empowerment and self-managed teams. While a significant number of organizations have shown successes in implementing TQM programs, it should be noted not all TQM efforts have been successful (Atchison, 1992; Brown, Hitchcock and Willard, 1994; Erickson, 1992; 
Harari, 1993; Holovick, 1995; Katz, 1993; Hubiak and O'Donnell, 1996; Whalen and Rahim, 1994; and Korukonda, Watson and Rajkumar, 1999).

\section{Enterprise Resource Planning}

Enterprise resource planning (ERP) is software that organizes and manages a company's business processes by sharing information across functional areas. It transforms transactional data like sales into useful information that supports business decisions in other parts of the company, such as manufacturing, inventory, procurement, invoicing, distribution, and accounting. In addition to managing all sorts of back-office functions, ERP connects with supply chain and customer management applications helping businesses share information both inside and outside the company. Thus, ERP serves as the backbone for an organization's information needs, as well as its ebusiness initiatives (Russell and Taylor III, 2003).

\section{HISTORY}

The company was founded approximately 35 years ago by the patriarch of the family who died at a fairly young age. The widow and children evolved into "figurehead ownership" hiring others to manage the company. This "armlength" management increasingly relied on a General Manager to run the company. There were a series of General Managers over a period of years. Approximately fifteen years ago an outside consultant (later to be referred to as a change agent as the role expanded) was hired to conduct supervisory development seminars for the company. These experiential seminars often analyzed the company's situation at a macro level company-wide as well as at a micro level by department. These analyses often developed insights into the company's operations that could be improved through team building or other improved communication and decision making strategies. However, the results were largely ignored as top management was never involved in the seminars. Approximately seven years ago an attempt was made by middle and lower management to develop communication and team building efforts resulting from the discussions of the seminars; however, these efforts were discontinued by the Manufacturing Manager. Six years ago a new General Manager took control of the company. He was autocratic and relied heavily on the Manufacturing Manager to keep everything "under control". Both managers favored those who worked for them, especially those individuals who followed their directions without questioning them. Major dissonance existed between the Manufacturing Manager and Engineering Manager that affected the culture throughout the organization. While several individuals in the organization suggested the Engineering Manager should be groomed for the General Manager position, the Manufacturing Manager specifically told the Engineering Manager he would never work for him. The Engineering Manager and other managers were often rebuffed by the General Manager and Manufacturing Manager and found it extremely difficult to integrate functions or effectively manage their work groups.

In December of 1999, the General Manager suddenly left the company due to health reasons. The family met to discuss whether to sell the company or make an effort to make it profitable and develop the third generation to take leadership over a two to three year period. The family decided not to sell the company and also selected the founder's daughter to run the company as President. As the daughter moved into the leadership of the company in January of 2000, she became increasingly aware of the prevailing mismanagement of the company in a number of areas.

\section{Consultant (Change Agent) Entry}

In March of 2000, a consultant was contacted and met with the Human Resource Director and Engineering Manager to discuss the situation in the company. This individual had successfully conducted a number of seminars in the company over several preceding years. The meeting with the consultant led to discussions with the new President and the formation of a team to plan what was needed to turn the company around. Consulting activities conducted by a number of different consultants in recent years were reviewed: 
1. A climate survey costing $\$ 30,000$ was conducted by a friend of the former General Manager. The survey revealed several issues to be investigated, but was discarded by the General Manager because it was embarrassing to the company.

2. A strategic planning seminar costing $\$ 12,000$ for two visits to the company was conducted by a different consultant. This seminar was considered to be helpful to the company.

3. An MRP consultant helped the company install a computerized MRP system. It was limited in scope; however, and included only selective sections of the manufacturing group. It was also very expensive as the consultant charged $\$ 5,000$ a day.

4. The current consultant and change agent was not associated with the consultants above, but had conducted numerous seminars for the company over a twenty-year period. This enabled this consultant to understand the problems in the various areas of the company and provided a level of trust with employees who had been part of these seminars and were now in middle management positions.

\section{Dysfunction Between Managers}

One issue requiring immediate attention concerned the dysfunction among managers in their interactions and meetings. Prior to the assumption of control by the founder's daughter, some managers would not show up to meetings or would be extremely negative during meetings. Individuals were rude; they showed a lack of respect for others; and, the meetings were poorly organized. Also, there was an overriding sense of control by the General Manager and Manufacturing Manager. Since many of the employees came from the same geographic area, there were relationships and interactions among middle and lower level managers that were negative dating back to high school. It was not unusual for lower and middle level managers with five to twelve years of experience to be fired for political reasons.

\section{Strategic Planning}

The new strategic planning team, consisting of the new President, the Engineering Manager, the Human Resource Director, and the consultant, decided on a stepwise integration of procedures designed to restructure the organization, to develop a team based approach to decision making, and to incorporate a new ERP design with the goal of developing current technology in the manufacturing process. The steps consisted of the following:

1. Present a seminar to top management on effective meetings including follow-up meetings. The consultant would attend these meetings and function as a process observer.

2. Conduct a personality assessment seminar with feedback for top and middle managers to improve communication effectiveness.

3. Conduct a seminar on management effectiveness using cross-functional teams at top and middle management levels.

4. Conduct individual interviews with top and middle managers to review the organizational structure of the company and assess suggestions for improvement within the total company.

5. Set up a cross-functional team to develop and analyze the adoption of an ERP system for the company including a cost-benefit analysis, timing, and selection of a vendor.

6. Conduct a reassessment of the position and needs of the company to determine the effectiveness of the intervention.

\section{Reorganization}

The primary goal of the reorganization was to use the existing experienced managers in the operation of the company. A process similar to TQM was developed as a strategy to empower lower level managers. The new President who thought she would occupy the Presidency for a short time period realized it would be necessary for her to occupy the position over a longer time frame. It was important during this time period of company development for her to be active in management rather than being just a figurehead. Accordingly, a speech was cowritten by the President and the consultant detailing the change in philosophy that was expected. The speech was delivered by the President to top management at the onset of the process. It was also announced by the President 
that the Engineering Manager was being groomed to be an "interim" General Manager and the third generation of the family business (the daughter's son) would be training in positions throughout the company in order to take over the leadership role in the company in the future.

It became increasingly obvious as more information surfaced about the previous mismanagement and current resistance to change by the Manufacturing Manager that significant change was needed in the operating structure. Further insights were provided through the interview process that was conducted with middle and lower managers. The position of Manufacturing Manager was eliminated and several functions of others previously under this manager were changed significantly. The President decided to retain the Manufacturing Manager since he had been with the company for many years and was in his mid-fifties nearing retirement. Talks with the Manufacturing Manager revealed he felt "over his head" in his position with the new technology changes, and he was happy to retain employment with substantial reduction in responsibility and pay. This was also a clear indicator to everyone that the President was serious about changing the business culture. With this single restructuring, the President was able to improve the functions performed by several other managers. Eventually the Engineering Manager was promoted to a new position entitled Vice President of Operations which was the former General Manager position. The functions of sales, finance, and human resources were removed from this position and were reassigned.

The new structure solidified the commitment of top management to developing the new culture within the organization, and provided an avenue for the simultaneous development of cross-functional teams at the top management and middle management levels. Prior to this time, middle managers were reluctant to commit to change since they had previously seen others who made this effort fired for political reasons. The structural changes also involved the decentralization of decision making and established a management style less authoritarian and more participative in nature.

\section{Team Building}

The infrastructure in the company for the development of effective team management was now in place. The structure of the organization was revised to eliminate pockets of resistance to a more empowering system of management. Training was provided to management and supervision on effective styles of leadership. There was total buy-in by the President, Vice President of Operations, and other key managers on using a team approach and team empowerment. The consultant was included as a facilitator in the formation, development, and implementation of a cross-functional product team and a cross-functional ERP selection team. All team members participated in the training sessions. There was a "new attitude" about the company's genuine interest in its management. The previous system of management with tight controls at the top was dismantled and replaced with a system that involved inclusion and individual respect of the employees.

The following actions were taken to move the company through the various stages of team development:

1. A seminar was conducted for the new top management group emphasizing team approaches to management.

2. A cross-functional team was constituted to guide the ERP selection team and to coordinate other developmental projects.

3. The ERP selection team was formed and given training regarding their processes, goals, and expectations.

4. Individual sessions were conducted with managers to insure a smooth transition due to the changes taking place.

5. The consultant met with managers at all levels for input and problem resolution as the team approach was implemented. This also involved meetings with the ERP selection team. 


\section{Results Of The Changes} following:

A significant number of positive results occurred with the changes made in the company including the

1. The President became supportive and involved in company management and the team approach that was implemented.

2. The former Engineering Manager is currently Vice President of Operations and the former Manufacturing Manager DOES work for him.

3. The third generation son has moved through assignments in marketing and information systems to further his personal development. He has also played a major role in the ERP selection team.

4. The former Manufacturing Manager is currently Maintenance and Grounds Manager with diminished power and authority. He seems to be enjoying his new role.

5. Other functions within the manufacturing sector of the company were reorganized. Key managers now have the opportunity to manage without the tight controls of the past. This has led to higher levels of productivity.

6. Top management interactions and meetings are much more productive. Managers go to each other's offices and work out differences they may have between them.

7. Attention has recently been given to restructuring Marketing, Human Resources, and the Office Management areas. Top management has stressed using a similar approach in these areas as was used in Operations.

8. There has been a major growth in company performance with output doubling in less than a year. Sales increased to over $\$ 12 \mathrm{M}$ in the same period.

9. The ERP Selection Team decided on an ERP system and the company is in early stages of implementation of the system.

10. The Product Team, assigned to recover a popular unprofitable product line, has turned around the profitability of that product line and is showing dramatic improvement in productivity and product performance. The product line showed a profit three months ahead of schedule and doubled the number of orders.

11. To provide for the continued progress within the Company, meetings between individual managers, top management, and the consultant are continuing and many negative issues are being eliminated before they become significant problems.

Notwithstanding the above successes, there are still some gaps in the new management structure since twelve managerial positions were significantly affected by the reorganization. However, there is a conflict resolution mechanism in place to assist in handling problems as they arise.

\section{SUMMARY}

Facing a number of significant internal issues relative to operations, the daughter of the founder of the company assumed control of the company. Working closely with an external consultant, a number of steps were taken to change the culture of the company to be more participative in nature. In addition to several seminars being conducted for the managerial group, the company was reorganized to include a team-based approach to management. In addition, an ERP system was recently implemented. The overall results of the changes have proven to be very positive.

\section{REFERENCES}

1. Atchison, T.A. (1992). TQM: "The Questionable Movement?" Healthcare/Financial Management, 46(3), March, $15-19$.

2. Brown, M.G., Hitchcock, D.E., \& Williard, M.L. (1994, July). "Why TQM Fails And What To Do About It.” Small Business Reports, $58-60$. 
3. Brown, Robert Bruce \& Harvey, Don. (2001). Human Resource Management. Upper Saddle River, New Jersey: Prentice-Hall. pp. $434-440$.

4. $\quad$ Chaudron, David (1995). "How to Improve Cross-Functional Teams," HR Focus, pp. 4 - 5.

5. Deming, W. Edwards. (1986). Out of Crisis. Cambridge, MA: Massachusetts Institute of Technology Center for Advanced Engineering Study. Chapter 2.

6. Erickson, T.J. (1992, July). "Beyond TQM: Creating The High Performance Business." Management Review, 81(7), $58-61$.

7. Goodman, Paul S., Devadas, Rukmini, and Griffith Hughson, Terri L., "Groups and Productivity: Analyzing the Effectiveness of Self-Managing Teams", in John P. Campbell, Richard J. Campbell, and Associates (Eds.), Productivity in Organizations, Jossey-Bass, San Francisco, 1988, pp. 295 - 327.

8. Hackman, J.R. (Ed.). Groups That Work And Those That Don't San Francisco: Josey-Bass, 1990.

9. Ivancevich, John M., and Matteson, Michael T., Organizational Behavior and Management, $3^{\text {rd }}$ ed., McGraw Hill, New York, 1993, p. 286.

10. Joinson, C. "Teams at Work." HR Magazine (1999), p. 30.

11. Katzenbach, Jon R., and Smith, Douglas, K., "The Discipline of Teams," Harvard Business Review, March-April 1993, p. 113.

12. Kirkman, Bradley L., Rosen, Benson, Gibson, Christina B., Teslik, Paul E., and McPherson, Simon O., "Five Challenges to Virtual Team Success: Lessons From Sabre, Inc.", Academy of Management Executive, Vol. 16, No. 3, 2002, p. 67.

13. Korukonda, Appa Rao, Watson, John G., Rajkumar, T.M. (1999). "Beyond Teams and Empowerment: A Couterpoint to Two Common Precepts in TQM.” SAM Advanced Management Journal, pp. 29 - 36.

14. Lawler, E.E.., III, Mohrman, S.A., \& Ledford, G.E., Jr. Employee Involvement and Total Quality Management (San Francisco: Josey-Bass, 1992).

15. LePine, J.A., Hanson, M.A., Borman, W.C., \& Motowidlo, S.J. "Contextual Performance and Teamwork: Implications for Staffing." Research in Personnel and Human Resources Management (2000), 19, pp. 53 90.

16. Luthans, Fred, Organizational Behavior, Tenth Edition, McGraw Hill/Irwin, New York, 2004, p. 454.

17. Marks, Michelle A., Sabella, Mark J., Burke, C. Shawn and Zaccaro, Stephen J. (2002), "The Impact of Cross Training on Team Effectiveness", Journal of Applied Psychology, Vol. 87, No. 1, pp. 3 - 13.

18. Offermann, Lynn R., and Spiros, Rebecca K., "The Science and Practice of Team Development: Improving the Link," Academy of Management Journal, Vol. 44, No. 2, 2001, pp. 376 - 392.

19. Robbins, H., \& Finley, M. Why Teams Don't Work (Princeton, N.J.: Peterson's/Pacesetters Books, 1995).

20. Russell, Roberta S., \& Taylor III, Bernard W., Operations Management. Upper Saddle River, New Jersey: Pearson Education, 2003, p. 542.

21. Stevens, M.J., \& Campion, M.A. "Staffing Work Teams: Development and Validation of a Selection Test for Teamwork Settings." Journal of Management (1999), 25, pp. 207 - 228.

22. Stevens, M.J., \& Campion, M.A. "The Knowledge, Skill, and Ability Requirements for Teamwork: Implications for Human Resource Management." Journal of Management (1994), 20, pp. 503 - 530.

23. $\quad$ Strozniak, P. “Teams at Work.” Industry Week (2000), p. 47.

24. Townsend, A. \& S. M. DeMarie. “Are You Ready for Virtual Teams?” HR Magazine (1996), 41, pp. 123 128.

25. Turner, Marlene E., (Ed.), Groups at Work: Theory and Research, Lawrence Erlbaum, Mahwah, N.J., 2001.

26. Yeatts, Dale E. and Hyten, Cloyd, High-Performing Self-Managed Work Teams: A Comparison of Theory and Practice, Sage, Thousand Oaks, Calif., 1998.

27. "Work Teams Have Their Work Cut Out for Them”, HR Focus, January 1993, p. 24. 
Notes 